\title{
Discutindo o currículo "por dentro": contribuições da pesquisa etnográfica
}

\author{
Maria Auxiliadora M. dos Santos Schmidt* \\ Tânia Maria F. Braga Garcia**
}

\begin{abstract}
RESUMO
Este artigo discute algumas contribuições que a pesquisa etnográfica pode dar à compreensão dos processos de reformulação curricular que têm sido levados a efeito nos diferentes sistemas de ensino. $\mathrm{O}$ potencial desse tipo de pesquisa é aqui discutido e apresentado a partir da análise dos resultados obtidos em estudos realizados como parte das atividades do Projeto Recriando Histórias de Pinhais, desenvolvido no âmbito do acordo de Cooperação Técnica, firmado entre a Universidade Federal do Paraná e a Prefeitura Municipal de Pinhais, a partir de 1997. Orientado principalmente para os saberes a serem ensinados em História, nas séries iniciais do ensino fundamental, as investigações mostraram formas pelas quais as professoras elaboraram e articularam saberes e práticas no seu trabalho cotidiano, permitindo explicitar alguns princípios que podem contribuir para o debate sobre a formulação e avaliação de propostas curriculares. Palavras-chave: currículo, pesquisa etnográfica, ensino de História.
\end{abstract}

\begin{abstract}
This article discusses some contributions that ethnographic research can give to be understood the changes proceedings in curriculum which had been done in different educational systems. The possibilities of this kind of educational research is discussed by the analysis of the results obtained from the studies done as part of the activities of the project named "Recri-

* Professora de Metodologia e de Prática de Ensino de História do Departamento de Teoria e Prática de Ensino do Setor de Educação da UFPR, professora do Programa de Pós-graduação em Educação da UFPR, atuando na linha "Currículo, conhecimento e saberes nas práticas escolares".

** Professora de Didática do Departamento de Teoria e Prática de Ensino do Setor de Educação da UFPR; doutoranda do Programa de Pós-graduação em Educação da Universidade de São Paulo.
\end{abstract}


ando Histórias de Pinhais", which was developed according to the Technical Cooperation agreement made between the Universidade Federal do Paraná and Prefeitura Municipal de Pinhais, in 1997. This research was directed for the historical knowledge which will be taught in initial grades of Escola Fundamental. The work shows some forms that the women teachers construct and articulate the knowledge and the practices in their daily work. This way the research explains some principles that can contribute for the debate about the production and the evaluation process of curriculum propositions.

Key-words: curriculum, ethnographic research, historical knowledge.

Nas últimas décadas, as escolas brasileiras têm sido envolvidas - com diferentes perspectivas - em reformas curriculares que pretendem reorganizálas, propondo conjuntos de saberes a serem ensinados ${ }^{1}$ aos alunos. Alternativas consideradas inovadoras são tomadas como referência para a organização de materiais cuja finalidade explícita é, boa parte das vezes, orientar as práticas escolares dentro de determinado sistema de ensino.

Na última metade da década de 90, por iniciativa do MEC, foram produzidos e divulgados os Parâmetros Curriculares Nacionais, que devem, de alguma forma, estar repercutindo na construção dos planos, projetos, programas das escolas brasileiras - parâmetros, diretrizes, não têm essa finalidade, a de orientar?

Neste artigo, pretende-se desenvolver algumas reflexões sobre esses processos de reformulação curricular a partir dos dados e análises resultantes de pesquisas realizadas por professoras da Universidade Federal do Paraná, com a participação de professores da rede municipal de ensino de Pinhais, região metropolitana de Curitiba.

Entende-se que as investigações realizadas, de natureza qualitativa e particularmente de cunho etnográfico, produziram elementos relevantes e estimuladores de discussões sobre outras vias para conceber e produzir as reformas curriculares nas escolas.

A partir da análise dos resultados obtidos, espera-se apontar a contribuição que as pesquisas na escola e na sala de aula podem dar à compreensão dos processos de mudança nas propostas curriculares. 


\section{Reconstruindo os saberes a serem ensinados em História}

A investigação que se discutirá a seguir foi realizada no contexto do Projeto Recriando a História de Pinhais e se orientou para o ensino de História nas séries iniciais do ensino fundamental. $\mathrm{O}$ foco principal do projeto foi discutir o conteúdo do saber a ser ensinado em História que estava presente nas propostas curriculares do município, particularmente nas séries em que se propõe o desenvolvimento de atividades sobre a localidade.

A perspectiva da História Local como alternativa para propor mudanças nos conteúdos dos saberes a serem ensinados já vem sendo tomada pelas escolas há pelo menos duas décadas, mas assumindo diferentes formas de abordagem. Assim, de forma geral, nas décadas de 70 e 80, as escolas desse nível de ensino desenvolviam conteúdos de Estudos Sociais, contemplando alguns aspectos do conhecimento histórico e geográfico, tomando como modelo curricular uma forma de organização em círculos concêntricos: o ensino deveria ser iniciado pelo mais próximo - a comunidade, o bairro - para depois incluir os estudos sobre a cidade, o país, o mundo.

Nas décadas de 80 e 90, ao lado de importantes discussões sobre a educação, a História e o ensino de História, constituem objeto de preocupações acadêmicas e também de muitos professores do ensino fundamental e médio. As propostas curriculares são colocadas em debate, particularmente frente às discussões de caráter psicológico e pedagógico sobre o papel do sujeito que aprende e as novas formas de se compreender o ensino. A História temática constitui-se, então, em proposta de saber ensinado, tomando-se a História Local como uma estratégia pedagógica fundamental.

Dentro do programa de formação continuada dos professores da rede de ensino de Pinhais, ${ }^{2}$ organizado e mantido pela Secretaria Municipal de Educação, elegeu-se como uma das prioridades o atendimento à necessidade, apontada pelos docentes, de discutir os conteúdos curriculares de História que compunham, naquele momento, os programas das escolas municipais, isto é, os saberes a serem ensinados presentes nos programas de história do município, além das formas metodológicas para desenvolver tais conteúdos. No ano

2 Considerando-se que a maior parte dos professores que atuam nas séries iniciais ( 1 . $^{\mathrm{a}} \mathrm{a}$ 4. ${ }^{a}$ séries) tem apenas a formação de magistério em nível médio, a Secretaria Municipal de Educação mantém programas de aperfeiçoamento continuado para seus professores nas diferentes áreas de conhecimento, com atividades realizadas em horários específicos, dentro da carga horária semanal dos professores. 
de 1996, foram realizados encontros de assessoramento pedagógico com os professores da terceira série.

Desses encontros, derivou-se a proposta de um projeto de extensão no qual as professoras pesquisadoras pudessem estabelecer contatos sistemáticos com o grupo de professores, respondendo de forma mais efetiva as suas demandas já expressas. Oficializou-se, então, por meio de um acordo de cooperação técnica assinado entre a Prefeitura Municipal de Pinhais e a Universidade Federal do Paraná, a elaboração e o desenvolvimento de um projeto que teria como prioridade estudar aspectos da história do Município e discutir a forma de trabalhar esses conteúdos com os alunos da rede municipal.

O primeiro encontro, já como atividade do Projeto Recriando a História de Pinhais, objetivou discutir o conceito de História Local, trazendo para os professores o debate sobre a compreensão da História Local como conteúdo ou como metodologia de ensino (OSSANA, 1994). Essa discussão foi imprescindível uma vez que os professores do município seguiam, naquele momento, a orientação curricular dos "círculos concêntricos", apoiada em outros princípios metodológicos. ${ }^{3}$

O segundo encontro teve como preocupação fundamental colocar o professor em contato com um dos elementos básicos do método de pesquisa específico do conhecimento histórico, qual seja, o trabalho com documentos. Essa questão manteve-se em foco nos encontros seguintes, quando a discussão foi orientada para as possibilidades do uso do documento histórico no ensino, especialmente nas séries iniciais.

Essa etapa de assessoramento foi concluída com um encontro para analisar e discutir as provas de uma gincana que seria realizada para identificar e coletar fontes no Município e, a partir delas, organizar formas de trabalho em sala de aula. Sob a orientação dos bolsistas participantes do projeto, cada uma das vinte escolas se organizou para localizar e coletar documentos, gravar entrevistas e depoimentos, registrar histórias contadas na região, descobrir e registrar brincadeiras e músicas presentes no lazer da comunidade, que passaram a compor um conjunto significativo de materiais extremamente rico para o estudo de História.

3 É importante destacar que as escolas do Município tomavam como referência o Currículo Básico produzido em 1992, quando Pinhais ainda era Distrito do Município de Piraquara. A elaboração desse documento se deu de forma similar ao que ocorreu em Curitiba, no Estado do Paraná e em outros locais, nas décadas de 80 e 90: produção por especialistas das áreas de conhecimento, com diferentes níveis de envolvimento ou participação dos professores. 
As provas da gincana, como já indicado, também foram pensadas e planejadas como estratégias e recursos de ensino. Assim, à medida que as provas eram realizadas, alunos e professoras desenvolviam, nas salas de aula, atividades de ensino e aprendizagem sobre os temas pesquisados, analisando documentos iconográficos e escritos, discutindo e comparando depoimentos colhidos, buscando articular seus conhecimentos prévios com as informações e dados coletados e, portanto, construindo coletivamente um certo tipo de conhecimento sobre aspectos da História de Pinhais.

Essas atividades desenvolvidas nas escolas geraram uma rica produção dos alunos - textos, desenhos, histórias em quadrinhos, cartazes, entrevistas foram sendo feitos e organizados pelas professoras -, conjunto de materiais que acabou por se constituir também num acervo de documentos sobre a História Local, que viria a ser utilizado na elaboração de diferentes materiais pedagógicos.

O processo de investigação que acompanhou as atividades propostas no projeto permitiu explicitar alguns princípios que podem contribuir para o debate sobre as formas pelas quais os sistemas de ensino têm pensado e realizado suas reformas curriculares.

O primeiro deles diz respeito à relação que os professores, sujeitos que ensinam, estabelecem com os saberes a serem ensinados. Depoimentos colhidos entre as professoras participantes revelaram que, ao buscar documentos, ao entrevistar moradores, ao percorrer as ruas em busca das casas mais antigas, as professoras puderam compreender que a História não se restringe ao conhecimento veiculado principalmente pelos manuais didáticos, instrumentos que tem imposto um conhecimento histórico sem sujeito; que o conteúdo da História pode ser encontrado em todo lugar; e que o conhecimento histórico está na experiência humana.

Em outras palavras, os procedimentos de identificação, seleção e proposição de conteúdos de ensino, no caso da História, podem também ser desenvolvidos pelos próprios professores, a partir do seu envolvimento com a sua própria realidade histórica, pressuposto básico para o trabalho de produção do conhecimento histórico.

O fato de trabalhar com a metodologia de pesquisa específica de uma área de conhecimento - e não com a pesquisa genericamente entendida - fez com que as professoras pudessem vivenciar e compreender uma determinada concepção de História e retomar o caminho que mostra o processo de produção do conhecimento histórico. Portanto, o segundo princípio, de natureza metodológica, está relacionado ao fato de que as professoras puderam identificar os indícios (conteúdos) da experiência humana em diferentes formas: a) 
na realidade cotidiana (olhando a natureza, a paisagem, a arquitetura); b) na tradição (festas, lazer); c) na memória (depoimentos) ; d) no conhecimento histórico sistematizado.

Trata-se, aqui, da possibilidade de aproximar o professor das formas como são produzidos os saberes, permitindo que se aproprie e/ou construa formas pelas quais esses saberes possam ser aprendidos. E, nessa direção, torna-se possível compreender que a forma pela qual se produz o conhecimento histórico hoje não é a mesma dos historiadores do século XIX e que, portanto, a forma de ensinar história não será a mesma também.

Um terceiro princípio deriva do entendimento de que a experiência humana apreendida, nessa perspectiva indiciária, não possui apenas uma dimensão localizada (bairro, cidade), mas identifica-se e articula-se com as experiências de outras pessoas, de outras épocas. Aqui, possibilita-se que o professor se aproprie dos saberes a serem ensinados a partir da atribuição de significados na perspectiva da História da própria humanidade.

Tais aprendizagens se tornaram possíveis para o grupo de professoras a partir de um conjunto de atividades que, ao longo de três anos e meio de trabalho, foram sendo desenvolvidas e discutidas do ponto de vista teórico. No entanto, a investigação permitiu compreender também que tais conhecimentos novos não são transpostos de forma direta para o conjunto de saberes que as professoras devem mobilizar e articular ao preparar e desenvolver suas aulas de História, cotidianamente, dando uma nova dimensão à idéia de que há também um processo de transformação dos saberes a serem ensinados em saberes ensinados.

Os materiais de apoio produzidos para servir de referência ao trabalho foram incorporados, em muitos casos, ao conjunto de outros materiais já disponíveis na escola e que, necessariamente, não se organizam a partir dos mesmos referenciais teórico-metodológicos. Na mesma perspectiva, ainda que a importância de usar documentos no ensino de História e também a forma pela qual podem ser usados fossem conhecidos pelas professoras, isso não significou uma incorporação dessas "estratégias" em todas as aulas de História. Tais constatações reafirmam a relevância dos processos de formação continuada de professores.

É importante destacar, por fim, que existem elementos novos a considerar quando são elaboradas novas propostas curriculares para os saberes a serem ensinados, elementos estes pertinentes aos próprios saberes, aos saberes presentes nos materiais de apoio didático, ou mesmo aos saberes presentes nas atividades produzidas pelos alunos.

Tais elementos foram explicitados nas investigações realizadas e apontados nos princípios aqui identificados, resultado de reflexões que podem ser 
compreendidas como primeiras aproximações e que apontam para a necessidade de pesquisas que busquem compreender melhor a forma como os saberes a serem ensinados se transformam em saberes ensinados e em saberes aprendidos. $^{4}$

Algumas considerações sobre a investigação etnográfica são feitas a seguir, com o objetivo de enfatizar seu potencial no desenvolvimento de estudos semelhantes aos aqui descritos.

\section{Buscando compreender as múltiplas dimensões do trabalho escolar}

A perspectiva etnográfica, qualitativa ou, ainda, interpretativa, relacionada com os estudos antropológicos e suas descrições detalhadas do que ocorre em contextos sociais e culturais específicos, foi introduzida sistematicamente na investigação educativa na década de 60, na Inglaterra, na década de 70, nos Estados Unidos, e também se difundiu no Brasil nos anos oitenta.

Um conjunto de artigos publicados na década de 80 (ROSEMBERG,1982; MELLO,1982; TONUCCI,1982; MARTINS,1982; ANDRÉ, 1983; FRANCO, 1984, entre outros) questionava aspectos relacionados aos processos de produção das pesquisas e também os seus resultados, insistindo na necessidade de buscar alternativas metodológicas para a investigação no campo da educação.

Dentre esses trabalhos, considera-se relevante, para os objetivos deste artigo, destacar o de autoria do pesquisador italiano TONUCCI (1982), traduzido com o título A pesquisa na escola: notas para debate. Depois de discutir os efeitos da pesquisa experimental na prática educativa, o autor levanta hipóteses para uma pesquisa na escola:

[...] pensamos que o pesquisador, que atua no âmbito social, deve encontrar outro modo de atuação. Sua contribuição deve ser

4 Nessa direção, está em fase de conclusão uma pesquisa que acompanhou as atividades de duas professoras na organização dos saberes de História a serem ensinados na terceira série, em uma escola da rede pública de ensino, com o objetivo de compreender elementos da transposição didática. Trata-se de dissertação de mestrado de Geyso Germinari, aluno do PPGE/UFPR. 
suficientemente técnica para que ele possa fazer afirmações documentadas e comprobatórias, as quais devem ser controladas internamente e referidas à pesquisa internacional; mas deve também ser adequada internamente à experiência real, apreendida globalmente, de modo a não se perder as características complexas do todo, mesmo quando a atenção está voltada para um aspecto singular. (TONUCCI, 1982, p. 66)

Ao indicar os níveis nos quais a pesquisa deverá operar, TONUCCI (1982) aponta um nível de descrição do "modo de se encontrar na especificidade do grupo escola" e afirma que tais exigências de pesquisa só podem ser satisfeitas se o pesquisador trabalhar "dentro da escola, entrando em contato direto com seus diversos componentes e respeitando suas características e exigências". É também nesse texto que parece se encontrar, pela primeira vez na literatura sobre o tema divulgada no país, a idéia de "passar de uma pesquisa SOBRE a escola para uma pesquisa NA escola." (TONUCCI, 1982, p. 66)

Afirmando-se na década de $90 \mathrm{com}$ diferentes enfoques e pressupostos teóricos, a investigação etnográfica reafirma essa perspectiva de estudar os processos educacionais em casos - que é considerada por ROCKWELL (2000) como uma das características da etnografia educativa latinoameriana. Essa perspectiva deve ser compreendida no sentido de que os pesquisadores reconhecem a forte presença do Estado como gestor da educação pública, definindo-se um contexto para os processos e fenômenos educacionais investigados. Para exemplificar, pode-se lembrar a centralização que tem marcado as reformas educativas nos diferentes países latinoamericanos.

Uma outra característica apontada por ROCKWELL (2000) diz respeito ao fato de que a pesquisa etnográfica latinoamericana, diferentemente do que ocorre em países anglosaxônicos, resiste à tendência de estudar as minorias. A consciência sobre a desigualdade social e educacional nos países da América Latina tem produzido um movimento da pesquisa em direção à maioria, ou seja, aos excluídos e ao sistema público de ensino que - em perigo de desaparecer - ainda, e de alguma forma, os acolhe.

Ao aceitar a idéia de que as normas educacionais oficiais não se incorporam à escola de acordo com sua formulação original, mas que são recebidas e interpretadas dentro de uma ordem institucional existente no espaço escolar, pode-se reconhecer os inúmeros desafios que a educação coloca hoje aos pesquisadores, inclusive na direção de compreender como é que as políticas neoliberais se expressam nas ações no interior da escola. Para ROCKWELL (1995, p. 14), conhecer melhor o processo escolar exige compreendê-lo como 
"un conjunto de relaciones y prácticas institucionalizadas historicamente, dentro de la cual el currículum oficial constituye sólo un nivel normativo."

Entendendo, ainda, que o significado do termo currículo é dado pelos próprios contextos em que se insere, incluindo-se o contexto de aula, é possível compreender a importância que as formas de pesquisar "na" sala de aula poderiam ter para as discussões voltadas a reformulações curriculares que os sistemas de ensino vêm realizando ao longo das duas últimas décadas no Brasil.

Tais reformas têm se caracterizado por um movimento que toma o currículo como "entidade", corporifica-o como norma e documento e projeta a possibilidade de que ele se constitua também em gerador de novas práticas no interior da escola. Desse ponto de vista, pode-se compreender a frustração ou o espanto do dirigente educacional ou do político que, tendo determinado a produção da proposta curricular mais avançada, obriga-se a afirmar que, apesar dela, o ensino não vai bem, porque os professores precisam aprender a ensinar dessa forma mais avançada e precisam de "capacitação".

Essa postura está explicitada na entrevista dada pelo Ministro da Educação Paulo Renato Souza (Folha de São Paulo, 04 dez. 2000, A6) a respeito dos resultados das provas aplicadas aos alunos nas escolas brasileiras. Ele afirma que o MEC esperava produzir um impacto imediato sobre a qualidade do ensino quando distribuiu os parâmetros curriculares nacionais e mais uma "nova publicação, os parâmetros em ação, para orientar, na prática, os professores". Trata-se de um equívoco que relaciona, de uma forma mecanicista e simplista, os saberes a serem ensinados com os saberes efetivamente ensinados e que projeta em "cursos de capacitação de professores" a possibilidade de solução dos problemas identificados a partir dos resultados do Sistema de Avaliação da Educação Básica (Saeb).

Ainda nessa direção, é possível reconhecer o mesmo tipo de equívoco quando se supõe que se pode garantir e avaliar os saberes aprendidos pelos alunos a partir do que se estabeleceu como saberes a serem ensinados - como se faz nas propostas curriculares -, desconsiderando-se o papel importantíssimo de mediador que o professor exerce entre essas duas instâncias da transposição didática e desconhecendo-se a natureza dessa atividade de mediação. Assim, diretrizes curriculares não podem ser tomadas como única referência de avaliação dos alunos com a finalidade de determinar a qualidade das escolas, sejam elas públicas ou particulares

Quando se intenta conhecer a escola na sua concreção, as investigações chamadas genericamente de etnográficas se mostram ricas e eficientes, pois permitem ao pesquisador se aproximar dos processos que são construídos no 
interior desse espaço, como um movimento local e particular, sem contudo negar a compreensão de que a construção de cada escola se dá num movimento histórico de amplo alcance ( EZPELETA; ROCKWELL, 1989).

Esse tipo de investigação pode permitir compreender melhor as formas pelas quais professores articulam e reelaboram práticas e saberes, formas essas que se manifestam cotidianamente em seu trabalho docente. E tal compreensão, segundo se espera ter apontado a partir do relato das investigações realizadas como parte do Projeto Recriando a História de Pinhais, poderia contribuir para transformar os caminhos pelos quais os sistemas têm feito as discussões, avaliações e reformulações curriculares junto às escolas e aos professores.

\section{REFERÊNCIAS}

ANDRÉ, M. E. D. A. Texto, contexto e significado: algumas sugestões na análise de dados qualitativos. Cadernos de Pesquisa, n. 45, p. 66-71, maio 1983.

CHEVALLARD, Y. La transposición didáctica: del saber sabio al saber a ser ensinado. Argentina: Aique Grupo Editor S.A.,1997.

EZPELETA, J. ; ROCKWELL, E. Pesquisa participante. Tradução: Francisco S. de Alencar Barbosa. 2. ed. São Paulo: Cortez/Editores Associados,1989.

FRANCO, M. L. B. Pesquisa educacional: algumas reflexões. Cadernos de Pesquisa, n. 51, p. 84-87, nov. 1984.

MELLO, G. N. Pesquisa em educação: questões teóricas e questões de método. Cadernos de Pesquisa, n. 40, p. 6-10, fev. 1982.

OSSANA, E. O. Una alternativa en la enseñanza de la Historia: el enfoque desde el local, el regional. In: VÁZQUEZ, J. Z. Enseñanza de la Historia. Buenos Aires, 1994. (Colección INTERAMER, 29).

ROCKWELL, E. De huellas, bardas y veredas: una historia cotidiana en la escuela. In: ROCKWELL, E. (Coord.). La escuela cotidiana. Mexico, D.F.: Fondo de Cultura Económica, 1995. 
ROCKWELL, E. Caminos e rumbos de la etnografía Latinoamericana. In: SIMPOSIO INTERAMERICANO DE INVESTIGACIÓN ETNOGRÁFICA EN EDUCACIÓN, 9., 2000, México. Anais... México: [s. n.], 2000.

ROSEMBERG, F. A pesquisa e a democratização do conhecimento. Cadernos de Pesquisa, n. 40, p. 4-6, fev. 1982.

TONUCCI, F. A pesquisa na escola: notas para debate. Cadernos de Pesqui$s a$, n. 41, p. 64-69, maio 1982. 
